\title{
Estimation Relationship Between Nuclear Energy Consumption and Economic Growth in Pakistan Using ARDL Approach
}

\author{
Zahoor Hussain Javed ${ }^{1, *}$, Muhammad Shabir ${ }^{2}$, Liaqat Ali Waseem ${ }^{3}$, Khalid Iqbal ${ }^{1}$ \\ and Mamoona Munir ${ }^{1}$ \\ 1Department of Economics, GC University Faisalabad, Pakistan; javedmarth@gcuf.edu..pk, khalidiqbal127@yahoo. \\ com,mamoonamunir3@gmail.com \\ 2Department of Sociology, GC University Faisalabad, Pakistan; drmshabbir@gcuf.edu.pk \\ ${ }^{3}$ Department of Geography, GC University Faisalabad, Pakistan; liaquat_fbs@yahoo.com
}

\begin{abstract}
Background/objectives: The use of nuclear energy plays very imperative role in economic growth. Method/findings: The present study employs ARDL approach to inspect alternative and nuclear power (\% of total power use) and GDP per capita (constant 2010 US\$) (economic growth) in Pakistan 1971-2014. Findings: The ARDL approach suggests that the dependent variable and regressor have long-term equilibrium but they are insignificant. The outcomes also propose that, both the long-term and short term, nuclear power utilization has a non-negative impact on economic growth. As a final point, the Granger causality analysis shows a unidirectional causality between alternative and nuclear power (\% of total power use) and GDP per capita (constant 2010 US\$). Application: Furthermore, ARDL test in this study suggests that nuclear energy is an effective solution to boost economic growth in Pakistan and gives useful information for policymakers.
\end{abstract}

Keywords: Nuclear Power, Economic Growth, ARDL Approach, Pakistan

\section{Introduction}

A few years ago, nuclear mishap in Fukushima, Japan was a gigantic strike to the status and belief in nuclear power creation, which make a number of countries to re-evaluate the mechanism of generation of nuclear power. The current financial upheaval might be limited in the developing or the developed countries if as the positive environmental effects of the nuclear power establishment are substantial. Thus, tremendous literature is available regarding the relationship flunked by use of nuclear power and economic growth. Abundant studies have been conducted in the past two decades to find an association flunked by these variables. The general findings of the studies show that the use of nuclear power and economic growth have a strong relationship. $\underline{1}$ For instance, Schurr ${ }^{2}$ has perceived a nonnegative liaison between economic growth and use of nuclear power.

Some countries are using nuclear power at large scale; others are introducing nuclear power first time. This is one of the main topics on Nuclear Power in the 21st century. This is well known that Pakistan is the slowest producer and consumer of nuclear power. Pakistan is not a member of the Nuclear Non-Proliferation Treaty (NPT) by which she eliminated from trade in nuclear materials or plant. More specifically, Pakistan uses nuclear energy for safetyrelated devices for achieving safeguard facilities. It has 02 nuclear power reactors under construction and five in operation and she uses 1355 MWe. $\underline{3}$

The Nuclear Engineering Research reported that Pakistan is a small state and she has low power demand compared to other countries. At this moment, Pakistan

${ }^{*}$ Author for correspondence 
has not top position in the list of expanding countries in the area of nuclear power. Currently, seven reactors are under construction in Russia, six in India and three in the Republic of Korea and two in Pakistan. However, the United States, France, Japan, and China are utilizing more nuclear power than all other countries in the world.

Power is a main pillar for the development of any nation. It supplies power to industrial sector by which goods and services are produced in the economy and in return it generates economic growth and brings opulence in society. In Refs. $\stackrel{4}{-7}$, authors emphasize an optimistic effect nuclear power on economic growth in several nations.

Power is a main input factor in production procedure, nevertheless, some researchers argued that it play a vital role along with production factors like capital, land, and technology in the production process $\underline{-}$ in line with Cheng and Lai ${ }^{9}$ who also argue use of power to boost the efficiency of other production factors. The endorsement of International Power Agency 10 demonstrates that the consumption of the power achievement, power-related emanations of $\mathrm{CO}_{2}$, and the demand and consumption of oil will increase more than twofold by 2050 . Therefore, without any sufficient amendment in government policies, consumers continuously utilize power more and more, thus dependency on fossil fuels would increase by which climate change and it would affect economic growth.

At this point, many countries have switched from the use of fossil fuels to hygienic surrogate power resources such as hydropower; nuclear power; wind power; and natural gas that will bail out them face escalating consumers demand and tumble the dependency on imported oil, nevertheless, Pakistan uses less nuclear energy than all these countries. The use of nuclear power brings price stabilization and reduces emission of greenhouse gases; consequently, it will increase supply of secure power. Thus, nuclear power is considered a carbon free source of power and this is the best solutions to secure power in the future and to prevent global warming. .11

It can be examined that both variables EG (economic growth) and NEC (nuclear energy consumption) have a non-negative tendency through all over the study period; nonetheless, the nuclear utilization raises in onwards period. $.2, \underline{13}$

The query arises hereby whether the uses of nuclear power affect the growth and development positively in shape of "by-products"
Actually, Pakistan has gifted with huge number of natural resources of power like wood, water, coal, gas, sunshine, oil, and wind, but unfortunately, these resources are not correctly consumed even though most of them stayed unused for decades. Subsequently, due to poor investments in power sector, thus power deficit is natural phenomenon for Pakistan. The economic growth and development in Pakistan faces enormous hurdle due to insufficient of power services. As a result, Pakistan is making try to promote nuclear power sector by which increase provision of power services to the Pakistanipeople. Thus, this will increase the per capita power consumption and growth of the country substantially. The consumption of energy will increase in South Asian countries because Pakistan, India, and Bangladesh consume more energy due to excess pressure of population. $\underline{ }^{14}$ Nevertheless, issues of use of nuclear energy have not been examined appropriately in Pakistan. In Pakistan, the nature has gifted a large number of resources, but these resources are not used properly. Therefore, in energy infrastructure, Pakistan faces serious energy shortfalls, because there is insufficient investment in energy infrastructure. Thus, Pakistan is making investment in the nuclear sector to enhance delivery of energy facilities to people in Pakistan.

\subsection{Background of the Problems}

The aforementioned studies on alternative and nuclear power (\% of total power use) and GDP per capita (constant 2010 US\$) (economic growth) show these has not been studied properly but it is considered very important for the benefit and welfare for the masses. The researchers found limited studies nuclear energy and economic growth. Consequently, more researches are needed in this field for significant improvement in Pakistan. Nevertheless, the alternative and null hypotheses are given as below:

$\mathrm{H}_{0}$. There is no cointegration between use of nuclear energy consumption and economic growth.

$\mathrm{H}_{1}$. There is cointegration between use of nuclear energy consumption and economic growth.

The null hypothesis of no long term liaison is $\mathrm{H}_{0}: ¥=¥_{1}$ $=0$ and it was checked under the direction of alternative hypothesis. The null hypothesis is $¥=¥_{1}$ which shows that there is no long-term liaison between variables, while in the alternative hypothesis is $¥ \neq ¥_{1} \neq 0$ which shows that there is long-run relationship between variables.

The remaining part of this research paper is organized as follows. The effect of nuclear power utilization on economic growth is briefed and discussed in the second 
section. Empirical approach and model specification is described in section 3. Section 4 demonstrates mechanism of data collection. The findings and discussion are depicted in sector 5. The finishing comments are presented in the last sector.

\subsection{Gap in Literature}

According to researchers' views, the study on alternative and nuclear power (\% of total power use) and GDP per capita (constant 2010 US\$) (economic growth) is required in a wider context in Pakistan. However, extensive literature on the alternative and nuclear power (\% of total power use) and GDP per capita (constant 2010 US\$) (economic growth) eminence showed that theoretical and empirical study regarding on alternative and nuclear power (\% of total power use) and GDP per capita (constant 2010 US\$) (economic growth) prestige is limited. In addition, researchers strongly recommended that there is excessive need to use of nuclear energy and economic growth in scenario of present era for the welfare of society.

In nutshell, the main purpose this research is to determine the liaison between GDP per capita (constant 2010 US\$) and use of nuclear power measured as alternative and nuclear power (\% of total power use) in the Pakistan for the period from 1971 to 2014. GDP per capita (constant 2010 US\$) has been taken as a proxy for economic growth and alternative and nuclear power (\% of total power use) for use of nuclear energy.

A detailed discussion of the principles and the mathematical foundations regarding alternative and nuclear power (\% of total power use) and GDP per capita (constant 2010 US\$) (economic growth) are presented in the subsequent sections along with the methodology by which relationship alternative and nuclear power (\% of total power use) and GDP per capita (constant 2010 US\$) (economic growth) are explored.

\section{Materials and Methods}

The mechanism of Cobb-Douglas Production Function is represented as:

$$
y=\mathrm{f}(\mathrm{nec})
$$

Here $y$ is Domestic Gross Productive per capita (constant 2010 US\$), nec is alternative and nuclear power
(\% of total power use). The equation may be predicted in a linear form such as below.

$$
y=\alpha+\beta_{1}(\mathrm{nec})+\mu
$$

Log of proxy for economic growth is GDP per capita (constant 2010 US\$), $\alpha$ is the intercept and $\beta_{1}$ is the coefficient of nec where nec is the log of nuclear power and $\mu$ is the error term. Expectation: $\alpha>0, \beta_{1}>0$.

\subsection{Model Specification}

The ARDL methodology for cointegrating test was established by Pesaran, Shin, and Smith (2001) which is valid regardless of whether the regressor variables are $\mathrm{I}(0), \mathrm{I}(1)$, or mutually cointegrated.

There are the basic steps of ARDL model is as follows

$$
\begin{aligned}
& \mathrm{Yt}=\beta 0+\sum_{i=1}^{p} \beta 1 \gamma \mathrm{t}_{1}-1+\sum_{i=0}^{q 1} \alpha 1 \mathrm{X} 1, \mathrm{t}_{-\mathrm{i}} \sum_{i=0}^{q^{2}} \alpha 2 \mathrm{X} 2, \mathrm{t}-\mathrm{i}_{+} \\
& \sum_{i=0}^{q 3} \alpha 3 \mathrm{X} 3, \mathrm{t}-{ }_{i}+\sum_{i=0}^{q 4} \alpha 4 \mathrm{X} 4, \mathrm{t}-{ }_{-\mathrm{i}+} \varepsilon t
\end{aligned}
$$

It may be extended as

$$
\begin{aligned}
& \mathrm{Yt}=\beta \mathrm{o}+\sum_{i=1}^{p} \beta 1 \gamma \mathrm{t}_{1}-i+\sum_{i=0}^{q 1} \alpha 1 \mathrm{X} 1, \mathrm{t}_{-\mathrm{i}} \\
& \sum_{i=0}^{q 2} \alpha 2 \mathrm{X} 2, \mathrm{t}-\mathrm{i}_{+} \sum_{i=0}^{q 3} \alpha 3 \mathrm{X} 3, \mathrm{t}-{ }_{i}+\sum_{i=0}^{q 4} \alpha 4 \mathrm{X} 4, \mathrm{t}-_{\mathrm{i}+} \\
& \theta 0 Y t_{1}+\theta 1 X 1, t_{-i+} \theta 2 X 2, t_{-i+} \theta 3 X 3, t_{-i+} \theta 4 X 4, t_{-i+} \varepsilon t
\end{aligned}
$$

The range of summation in various term in Equation (2) are represented from 1 to $\mathrm{q} 1,0$ to $\mathrm{q} 2,0$ to $\mathrm{q} 3$ and 0 to q4, respectively.

The appropriate values for maximum lags, $\mathrm{p}, \mathrm{q} 1, \mathrm{q} 2, \mathrm{q} 3$ and $\mathrm{q} 4$ are selected by using the information criterion to select for using bound test again as below

$$
\begin{aligned}
& \mathrm{Yt}=\beta \mathrm{o}+\sum_{i=1}^{p} \beta 1 \gamma \mathrm{t}_{1}-i+\sum_{i=0}^{q 1} \alpha 1 \mathrm{X} 1, \mathrm{t}_{-\mathrm{i}} \\
& \sum_{i=0}^{q 2} \alpha 2 \mathrm{X} 2, \mathrm{t}-\mathrm{i}_{+} \sum_{i=0}^{q 3} \alpha 3 \mathrm{X} 3, \mathrm{t}-{ }_{i}+\sum_{i=0}^{q 4} \alpha 4 \mathrm{X} 4, \mathrm{t}--_{\mathrm{i}+} \\
& \theta 0 Y t_{1}+\theta 1 X 1, t_{-i+} \theta 2 X 2, t_{-i+} \theta 3 X 3, t_{-i+} \theta 4 X 4, t_{-i+} \varepsilon t
\end{aligned}
$$

Perform an "F-test" for acceptation or rejection of null hypothesis and alternative null hypothesis.

In each case, the lower bounds is based on the assumption that all the variables are $I(0)$, and the upper 
bound is based on the assumption that all the variables are $I(1)$.

$$
Y_{t}=\beta 0+\alpha 1 X 1, t+\alpha 2 X 2, t+\alpha 3 X 3, t+\alpha 4 X 4, t+\varepsilon t
$$

as well as the usual ECM:

$$
\begin{aligned}
& \Delta \mathrm{Yt}=\beta \mathrm{o}+\sum_{i=1}^{p} \beta 1 \Delta \gamma \mathrm{t}_{1}-i+\sum_{i=0}^{p 1} \alpha 1 \Delta \mathrm{X} 1, \mathrm{t}_{-\mathrm{i}} \\
& \sum_{i=0}^{q 2} \alpha 2 \Delta \mathrm{X} 2, \mathrm{t}-\mathrm{i}_{+} \sum_{i=0}^{q^{3}} \alpha 3 \Delta \mathrm{X} 3, \mathrm{t}-{ }_{i}+ \\
& \sum_{i=0}^{q 4} \alpha 4 \Delta \mathrm{X} 4, \mathrm{t}-{ }_{\mathrm{i}+} \Omega Z_{t-1}+\varepsilon t
\end{aligned}
$$

where $\mathbf{Z}_{\mathrm{t}-1}=\mathbf{Y}_{\mathrm{t}-1}-\mathrm{a}_{0}-\alpha_{1} \mathrm{X} 1, \mathrm{t}-1-\alpha 2 \mathrm{X} 2, \mathrm{t}-1-$ $\alpha 3 \mathrm{X} 3, \mathrm{t}-1-\alpha 4 \mathrm{X} 4, \mathrm{t}-1$

$\mathrm{ADF}$ test is used to check stationarity of the variables at $I(0)$ or $I(1)$. The bound test with an ARDL methodology is used to check the validity of long-run associations of variables.

The ARDL approach is usage to conclude the relationship between alternative and nuclear power ( $\%$ of total power use) and GDP per capita (constant 2010 US\$) (economic growth. The ARDL econometric technique familiarized by Pesaran et al. $\underline{\underline{16}}$ and adopted. $\underline{17}^{-}$This technique is several time better over the cointegration technique represented by the authors. $\underline{18, \underline{19}}$ This approach is adopted small sample and it has not imposed condition the variables have the same order of integration. Furthermore, dependent and independent variables are explained by their past.

In the next step, computed value of the F-statistics are compare with tabulated critical bounds values, which were depicted by Granger. 20 The study will find a long-run relationship between variables. Thus, the null hypothesis of a long-term alliance is refused. Furthermore, thevalue of $F$-statistic surpassed over critical bound values, despite orders of integration of the variables is $I(0)$ or $I(1)$, it means that there is long-term liaison between variables. In the same way, if the computed values of $F$-statistics are below the critical value, the null hypothesis is not rejected and it shows that there is no long-term relationship between dependent variable and regressor. Furthermore, if the F-statistic values fall between these two bounds critical values then findings are undecided.

The mechanism of ARDL model is estimated as below:

$$
\Delta \ln y t=\alpha+\sum_{k=1}^{m} \alpha 1 \mathrm{k} \Delta \ln \mathrm{y} t-k+\sum_{k=0}^{m 1} \alpha 2 \Delta \ln (n e) t-k+\psi i(3)
$$

Thus, Equation (6) estimates and observes the shortrun behaviors of the variables in the error-correction model and speed of adjustment towards long-term equilibrium.

$$
\begin{aligned}
\Delta \text { lnnet }=\alpha+\sum_{k=1}^{m} \alpha 1 \mathrm{k} \Delta \ln \mathrm{net}-k+ \\
\sum_{k=0}^{m 1} \alpha 2 \Delta \ln (y) t-k+¥ e c t_{-1}+\psi i
\end{aligned}
$$

As a final point, for reliable findings a stability test is used to check the fitness of model. The cumulative sum of CUSUM and CUSUMSQ tests depicts stability of the model. The both tests are employed at the $5 \%$ significance level and they indicate the null hypothesis is not rejected because the graphs of the CUSUM and CUSUMSQ statistics remain inside the boundary lines. Thus, it shows that model is fit for analysis and findings of analysis are confirmed.

\subsection{Mechanism of Granger Causality Test}

The estimation of cointegration shows a causal relationship flunked by dependent variable and regressors, but the path of causality is not clear. The path of causality among variables can be investigated by employing the Granger Causality test. $\underline{21}, 22$ If the cointegration flunked by variables exists at non-stationary level, then, Granger causality test among the variables is verified through system of the following Equation (7):

$$
\begin{aligned}
& (1-L)\left[\begin{array}{c}
y t \\
n e c t
\end{array}\right]=\left[\begin{array}{c}
c 1 \\
c 2
\end{array}\right]+\sum_{i=1}^{q}(1-\mathrm{L})\left[\begin{array}{lll}
a 1 & 1 i & a 12 i \\
a 2 & 1 i & a 22 i
\end{array}\right] \\
& +\left[\begin{array}{c}
y t-1 \\
n e c t-1
\end{array}\right]+\left[\begin{array}{l}
\lambda 1 \\
\lambda 2
\end{array}\right](E C T 1)+\left[\begin{array}{c}
\partial 1 t \\
\partial 2 t
\end{array}\right]
\end{aligned}
$$

\section{Data Collection}

In order to find the relationship flunked by use of nuclear power and economic growth, the data for economic growth and nuclear power utilization have been taken from world indicator for the period 1971-2014. Economic growth is proxy for GDP per capita (constant 2010 US\$) and use of nuclear power is proxy for alternative and nuclear power (\% of total power use). The use of GDP per capita is more suitable than gross national product (GNP) because goods and services which are fabricated within the nation not with the use of nuclear power. The GDP per capita is measured in USA currency as a dollar. The use of nuclear power is measured in unit of Terawatthours (TWh). 


\section{Results and Discussions}

The ARDL model is employed if the variables are $I(1)$ or $I(0)$. The use of ARDL is not suitable for cointegration test when order of integration of the variables surpassed $I(1)$. For that reason, before applying of the ARDL, it is most imperative to execute a unit root test to find order of cointegration. In this study, the Dickey Fuller generalized least squares test are used to check stationarity of data. The findings of this test are more reliable compared with others tests. Thus findings of Ref. 23 test are predicted in Table 1 . The results predict the logarithmic form of one variable is non-stationary and other is stationary, thus they are integrated at $I(0)$ and $I(1)$.

\subsection{ARDL Cointegration Approach}

Before employing ARDL bound test, the choice of the optimal lag order of variables is most important because it affects the statistical value of the $F$-test. The Lag order selection criteria are used to find the optimal lag. The findings are presented in Table 2, which remarks the optimal lag order is 1 .

With the help of optimal lag order, the F-test is used to investigate the cointegrating liaison between the variables. The findings points out that the $F$-statistics values do not surpassed the lower critical and the upper critical bound at the 5\% and $10 \%$ levels. The outcomes are depicted in Table 3. In Ref., $\underline{19}$ author suggested that the null hypothesis of no long-run liaison is accepted and the alternative null hypothesis of long-term liaison is rejected. The findings of ARDL bound test verified that alternative and nuclear power (\% of total power use) and GDP per capita (constant 2010 US\$) (economic growth) have not a long-run relationship because the calculated $F$-statistics values do not exceed the upper and lower critical bounds, it infers that there was no a long-term

Table 1. Findings of DF-GLS test

\begin{tabular}{|l|l|l|l|l|l|}
\hline $\begin{array}{l}\text { Vari- } \\
\text { ables }\end{array}$ & $\begin{array}{l}\text { SIC } \\
\text { lag }\end{array}$ & $\begin{array}{l}\text { Statistics } \\
\text { value of } \\
\text { DFGLS }\end{array}$ & $\begin{array}{l}\text { SIC } \\
\text { lag }\end{array}$ & $\begin{array}{l}\text { Stat } \\
\text { value } \\
\text { of } \\
\text { DFGLS } \\
\text { Ist diff }\end{array}$ & Decision \\
\hline Ln $y_{t}$ & 5 & $-5.71^{*}$ & 0 & $-10.07^{*}$ & $\mathrm{I}(0)$ \\
\hline $\begin{array}{l}\text { Ln } \\
(\mathrm{ne})_{\mathrm{t}}\end{array}$ & 0 & -1.63 & 0 & $-5.55^{*}$ & $\mathrm{I}(1)$ \\
\hline
\end{tabular}

Note: ${ }^{* *},{ }^{*}$ indicate statistical significance level at $1 \%$ and $5 \%$, respectively.
Table 2. The findings of lag order selection criteria

\begin{tabular}{|l|l|l|l|l|l|l|}
\hline Lag & Log L & LR & FPE & AIC & SC & HQ \\
\hline 0 & -321.81 & NA & 24838.82 & 15.795 & 15.879 & 15.826 \\
\hline 1 & -219.15 & $190.29^{*}$ & $201.95^{*}$ & $10.983^{*}$ & $11.23^{*}$ & $11.07^{*}$ \\
\hline 2 & -217.01 & 3.759 & 221.55 & 11.07 & 11.49 & 11.22 \\
\hline 3 & -215.83 & 1.96 & 255.28 & 11.21 & 11.79 & 11.42 \\
\hline 4 & -212.29 & 5.52 & 263.11 & 11.23 & 11.98 & 11.50 \\
\hline
\end{tabular}

Note: ${ }^{*}$ indicates the optimal lag order.

Table 3. Findings of ARDL test

\begin{tabular}{|l|l|l|l|}
\hline \multicolumn{2}{|l|}{ Panel1: ARDL test } & \multicolumn{2}{l|}{ Panel II: Diagnostics tests } \\
\hline $\begin{array}{l}\text { Assessed } \\
\text { equation }\end{array}$ & $\begin{array}{l}\log \left(y_{\mathrm{t}}\right)= \\
\mathrm{f}\left(\log \left(\mathrm{ne}_{\mathrm{t}}\right)\right.\end{array}$ & $R^{2}=0.26$ & $\begin{array}{l}\text { Adjusted- } R^{2} \\
=0.25\end{array}$ \\
\hline \multicolumn{2}{|l|}{ Optimal lag level $=1$} & F-stat $=15.71^{*}$ & Prob $=0.00$ \\
\hline $\begin{array}{l}\text { F-Statistics } \\
\text { (Wald statistics) }\end{array}$ & 2.023 & D.W $=2.01$ \\
\hline $\begin{array}{l}\text { Pesaran et al. } \\
(2001)\end{array}$ & Critical & $\begin{array}{l}\text { Breusch-Godfrey LM test: } \\
0.49(0.31)\end{array}$ \\
\hline & values & $\begin{array}{l}\text { Hetroskdasticity ARCH test: } \\
0.94(0.68)\end{array}$ \\
\hline Significance & Level & Upper bound critical values \\
\hline $1 \%$ & 3.74 & 5.06 \\
\hline $5 \%$ & 2.86 & 4.01 \\
\hline $10 \%$ & 2.45 & 3.52 \\
\hline
\end{tabular}

Note: ${ }^{\star}$ no statistical significance even at $10 \%$ level.

liaison between dependent variable and regressors. It is verified that dependent variable and regressor have not a long-run relationship between each other, which is represented in Table 4 . The coefficient of nuclear power is nonnegative, but it is significant which suggest that there is a positive influence of the use of nuclear power on economic growth in Pakistan, but there is not a long-run relationship because the conditions of Wald test are not justified.

The long-run elasticity nuclear power for economic growth is 0.88 , which indicate that $0.88 \%$ boost up in economic growth but it is insignificant even at $5 \%$ level

Table 4. Estimation of long-run results

\begin{tabular}{|l|l|l|l|l|}
\hline Var & Coeff & Stand error & t-Stat & Pro \\
\hline C & -0.21 & 0.48 & 0.12 & 0.12 \\
\hline$n e_{t}$ & 0.88 & 0.42 & 1.58 & 0.90 \\
\hline
\end{tabular}

Note: ${ }^{*}$ shows significant level $1 \%$. 
if a $1 \%$ increase in use of nuclear power. But, the use of nuclear power does not appear to be an imperative factor on economic growth in the long term. The findings suggest that there is a nonnegative liaison between dependent variable and regressor in Pakistan's economy. The findings of this study confirm the result of Granger $\underline{20}$, Yoo and Kwak ${ }^{21}$ and Elliott et al. $\underline{22}$ The estimated shortterm coefficient of $\mathrm{Ecm}(\mathrm{t}-1)$ is -0.02 in error-correction model which is negative and statistically insignificant. This error-correction divulges the deviation from the long-term balanced level of economic growth in one year and speed of the adjustment is represented by $2 \%$ in the next year, but it is insignificant.

\subsection{The VECM}

The findings of the GCT are presented in Table 5. The findings show nuclear energy consumption and economic growth have a unidirectional liaison in a short-run. These findings imply that the economic growth and use of nuclear power have unidirectional causality.

\subsection{The Instability Test Results for Long- term}

The parameters create unreliability in the model, thus, CUSUM and USUMSQ technique are practiced to determine the stability of the parameters. Therefore, results of the CUSUM and USUMSQ predict that all coefficients remain stable and credible in the errorcorrection model because the graph of both tests in Figures 1 and 2 remain within the boundaries lines and this shows the stability of parameters in this model over the study period. So, the selected model is fit for analysis, thus policy decision-maker can use these results for the welfare of society.

Graph of cumulative sum of recursive residuals

For short-run period. This study also uses CUSUM and USUMSQ to find the steadiness of the parameters in the

Table 5. Error correction depiction of ARDL

\begin{tabular}{|l|l|l|l|}
\hline \multicolumn{3}{|l|}{ Short-run F-Stat (Prob) } & \\
\hline Dep variable & $\begin{array}{l}\Delta \\
(\log (y))\end{array}$ & $\Delta(\log ($ ne $))$ & ECTt-1 (t-Stat) \\
\hline$\Delta(\log (y))$ & & $-0.52(-2.02)$ & $-0.02(-0.89)$ \\
\hline$\Delta(\log ($ nec $))$ & $\begin{array}{l}-0.31 \\
(-2.79)\end{array}$ & - & \\
\hline
\end{tabular}

Note: ${ }^{*}$ indicate statistical significance at $5 \%$ level.

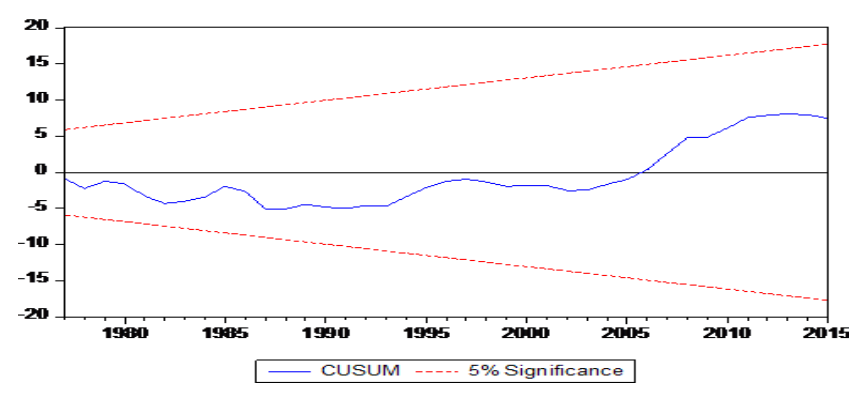

Figure 1. Recursive residuals and cumulative sum test results.

Graph of cumulative sum square of recursive residuals

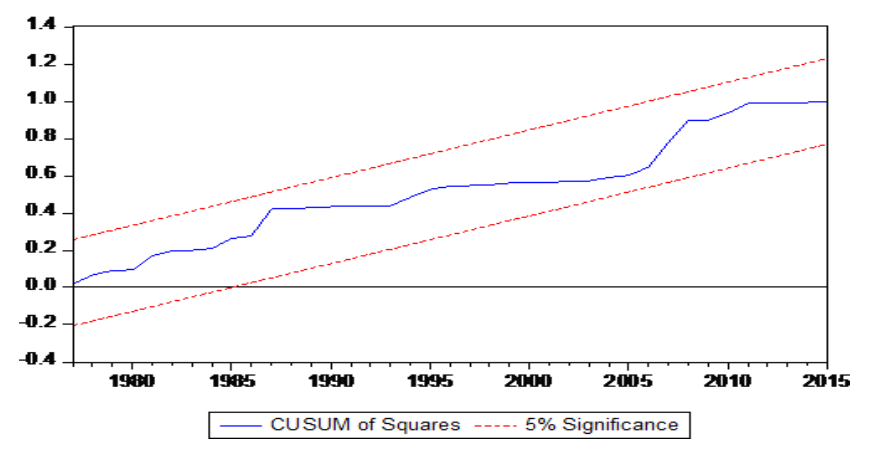

Figure 2. Cumulative sum of squared recursive residuals test results.

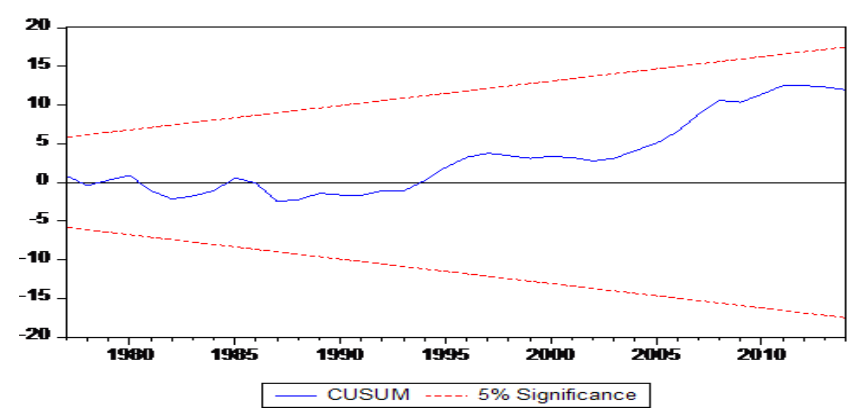

Figure 3. Recursive residuals and cumulative sum test results.

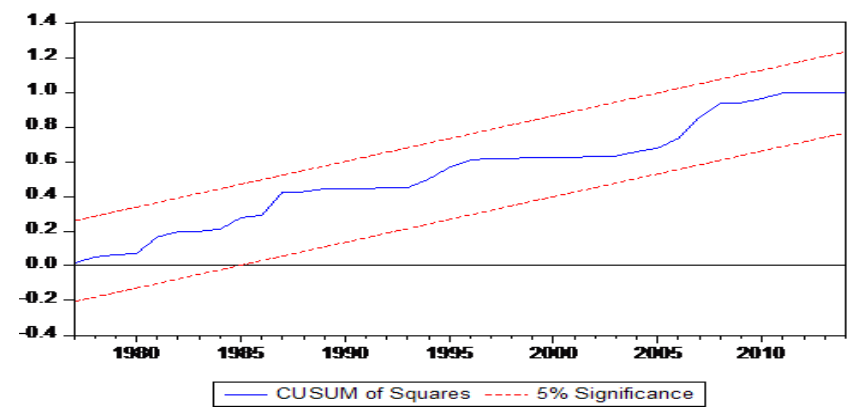

Figure 4. Cumulative sum of squared recursive residuals test results. 
model. All coefficients remain stable and credible in the error-correction model because the graph of both Figures 3 and 4 remain within the critical boundaries. Therefore, the selected model is fit for analysis in short period also.

\subsection{Recursive Coefficient Test for Stability}

The recursive coefficient test for stability depicts the model is fit for analysis, because graph of all variables lays between the boundaries lines as shown in Figure 5 .
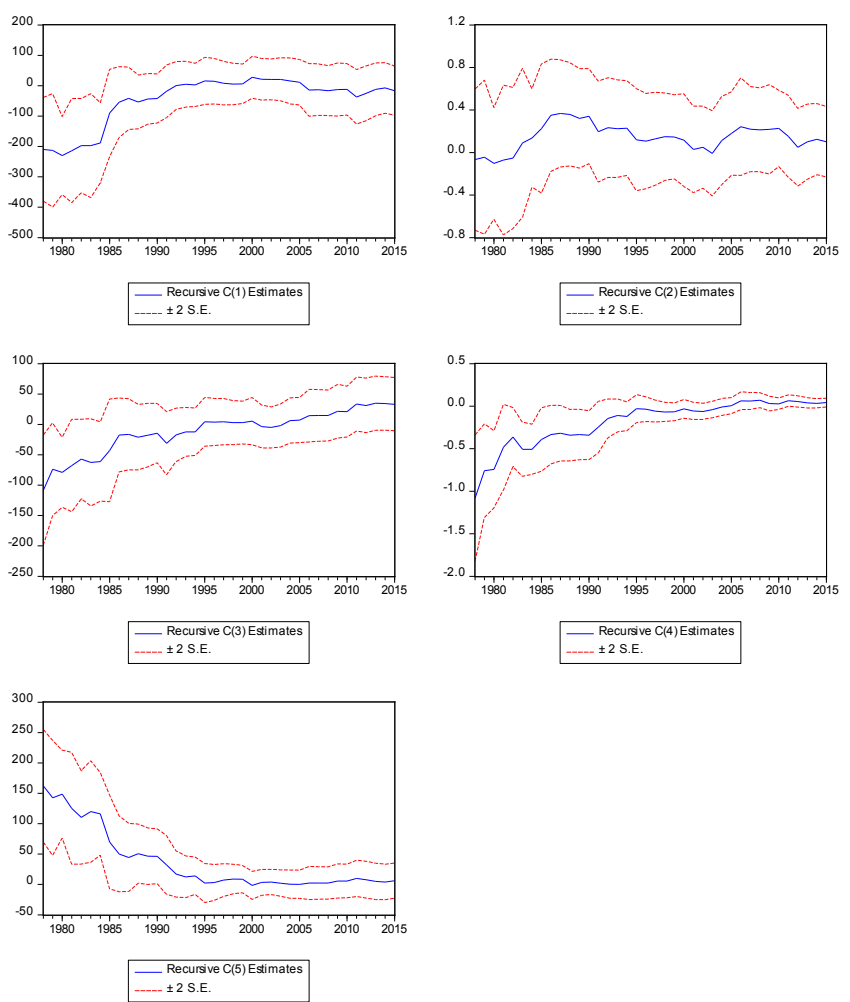

Figure 5. Recursive coefficient test for stability depicts the model is fit.

\section{Findings/Conclusion}

This research observes the relationship between nuclear power and economic growth in Pakistan by using ARDL method and Granger Causality technique. The conclusions suggested that nuclear energy and economic growth have not a long-run relationship between each other and similarly in a short-run. This study discovers that use of nuclear power causes a significant increase in economic growth in Pakistan but it is not in a long term.

The estimated short-run coefficient of $\mathrm{Ecm}(\mathrm{t}-1)$ is -0.02 in error-correction model which is negative and statistically insignificant. This error-correction reveals the deviance from the long-term balanced level of economic growth in one year and speed of the adjustment is represented by $2 \%$ over the next year but it is insignificant. The GC test shows nuclear power and economic growths have unidirectional causal relationship. Thus, these findings have imperative suggestion for policy making. The findings consist with the results of specifically; the findings show that if the nation will use more unit of nuclear power in coming decades, it will achieve economic stability and sustainable growth in future.

\section{References}

1. Frewer H, Altvater W. Technology transfer by industry for the construction of nuclear power plants. Ann Nucl Power. 1977; 4:235-48.

2. Schurr SH. Power abundance and economic progress. Ann Nucl Power. 1983;10:111-7.

3. Electricity information. [cited 2017]. https://www.iea.org/ statistics/electricity/.

4. Shafiei S, Salim RA. Non-renewable and renewable power consumption and $\mathrm{CO} 2$ emissions in OECD countries: a comparative analysis. Power Policy. 2014;66:547-56.

5. Yoo SH, Kwak SJ, Kim TY. Assessing the benefits of the greenhouse gas emission reduction policy: a pilot case study of Korea. Int J Environ Pollut. 2004;15(5):553-67.

6. Xue B, Geng Y, Müller K, Lu C, Ren W. Understanding the causality flunked by carbon dioxide emission, fossil power consumption and economic growth in developed countries: an empirical study. Sustainability. 2014;6:1037-45.

7. Ferguson R, Wilkinson W, Hill R. Electricity use and economic development. Power Policy. 2000;28:923-34.

8. Kwak SJ, Yoo SH, Kim CJ. Evaluation of the national nuclear power R\&D projects in Korea: multi-attribute utility analysis. Int J Global Power Issues. 2003;20:119-38.

9. Cheng BS, Lai WL. An investigation of co-integration and causality flunked by power consumption and economic activity in Taiwan. Power Econ. 1997;19:435-44.

10. Power balances of non-OECD countries. [cited 2009]. https://www.oecd-ilibrary.org/energy/energy-balances-ofnon-oecd-countries_19962843.

11. Silva S, Soares I, Pinho C. The impact of renewable power sources on economic growth and CO2 emissions-a SVAR approach. Eur Res Stud J. 2012;15(4):133-44.

12. Shahbaz M. Does financial instability increase environmental degradation? Fresh evidence from Pakistan. Econ Model. 2013;33:537-44.

13. Shiu A, Lam PL. Electricity consumption and economic growth in Pakistan. Pow Policy. 2004;32:47-54. 
14. Geweke J, Meese R, Dent W. Comparing alternative tests for causality in temporal systems: analytic results and experimental evidence. J Econ. 1983;21:161-194.

15. Pesaran MH, Shin Y. An autoregressive distributed lag modeling approach to co-integration analysis. In: Econometrics and economic theory in the 20th century: the Ragnar Frisch Centennial Symposium; 1998. P. 371-413.

16. Pesaran MH, Shin Y, Smith RJ. Bounds testing approaches to the analysis of level relationships. J Appl Econ. 2001;16(3): 289-326.

17. Englev RF, Granger CWJ. Co-integration and error correction: representation, estimation, and testing. Econometrica. 1987;55:51-276.

18. Johansen S, Juselius K. Maximum likelihood estimation and inference on co-integration with application to money demand. Oxf Bull Econ Stat. 1990;52:169-210.
19. An autoregressive distributed lag modeling approach to co-integration analysis. [cited 1991]. http://citeseerx.ist. psu.edu/viewdoc/download?doi=10.1.1.153.3246\&rep=rep $1 \&$ type $=$ pdf.

20. Granger CWJ. Investigating causal relation by econometric and cross-sectional method. Econometrica. 1969;37:424-38.

21. Yoo SH, Kwak SJ. Information technology and economic development in Korea: a causality study. Int J Technol Manag. 2009;27:57-67.

22. Elliott G, Rothenberg TJ, Stock JH. Efficient tests for an autoregressive unit root. Econometrica. 1996;64:813-36. 